\title{
Theoretical Calculation and Simulation Analysis of No-load Torque of Main Reducer
}

\author{
Jinli Xu and Ganlin Sheng* \\ ${ }^{2}$ School of Mechanical and Electrical Wuhan University of technology, Wuhan 430070, China \\ *Corresponding author
}

\begin{abstract}
Bearing support stiffness of driving bevel gear is the main source of vibration and noise of automobile rear axle main reducer. There are closed relations between bearing preload and no-load torque of main reducer and support stiffness. Taking the car's main reducer as the research object, this paper explored the closed relations while the driving bevel gear bearing of main reducer for automobile was under preload. We obtained the suitable suitable stiffness of the main reducer bearing by simulation, after which we got the optimum preload and no-load torque when assembling. This study provides a theoretical support for reducing vibration and noise of main reducer.
\end{abstract}

Keywords-main reducer; tapered roller bearing; bearing preload; no-load torque; vibration

\section{INTRODUCTION}

The assembly quality of the main reducer will directly affect the overall performance of the vehicle, and the key is the assembly of the driving bevel gear and the passive bevel gear. In order to ensure the correct meshing of the teeth, avoiding the occurrence of mutual movement, and smaller transmission shock noise vibration, it is required that the assembly process of the main bearing impose a certain axial preload. So the driving bevel gear can rotate freely, besides, which also has enough support stiffness during the working process of main reducer. In the assembly process of the main reducer, it is difficult to detected the preload value of the bearing of driving bevel gear directly. In this paper, the main reducer is used to detect the bearing preload by the value of the no-load torque in the actual project. Therefore,the value of no-load torque is one of the control parameters of the system's support stiffness in practical production.

According to the actual production standards given by the long-term experience, no-load torque is required to be controlled between 0.6 and $0.9 \mathrm{~N} \cdot \mathrm{m}$. In order to find out the best value from this interval, this paper analyzes the correlationship between no-load torque, bearing stiffness and bearing preload, then obtain the best bearing preload and noload torque by determining the best bearing stiffness. This study provides a theoretical reference for the vibration and noise reduction of the rear axle.

\section{MATHEMATICAL MODEL ANALYSIS OF NO-LOAD TORQUE}

\section{A. The Concept and Calculation Model of No-load Torque}

The no-load torque is the moment required to rotate the main reducer flange when the driving bevel gear and the bearing of driving bevel gear are assembled, and the locknut is tightened to tighten the bearing. The torque balance model in the detection process can be expressed by Figure. 1 .

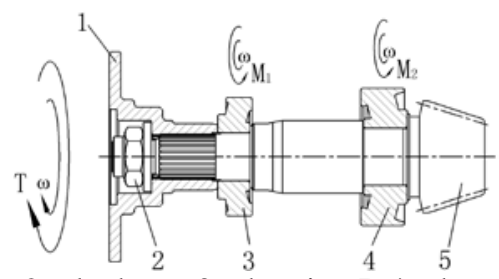

1-flange; 2-locknut; 3-bearing I; 4-bearing II; 5driving bevel gear.

FIGURE I. SYSTEM TORQUE BALANCE DIAGRAM FOR DETECTING NO-LOAD TORQUE

The no-load torque calculation equation is:

$$
T=M_{1}+M_{2}
$$

$M_{1}$ is the friction torque of bearing $\mathrm{I}$ and $M_{2}$ is the friction torque of bearing II . From the above analysis, it is required to solve the friction torque of the two bearings of driving bevel gear in order to get the value of no-load torque.

\section{B. Theoretical Calculation of Frictional Moment of Tapered Roller Bearing}

In general, the friction of rolling bearing is composed of the following parts [1]: 1.Pure rolling friction caused by the elastic hysteresis; 2.Sliding friction caused by the sliding of rolling contact surface; 3.Friction caused by spin sliding at the normal direction of the contact surface; 4.Pure sliding friction on the sliding contact surface; 5.Viscous friction of the lubricant (mainly grease). The friction torque value of 2 and 3 are relatively small, which do not need to be considered. In summary, the geometric structure and mechanical analysis under axial load of tapered roller bearings and single rollers can be expressed by Figure.2 and Figure.3 [2].

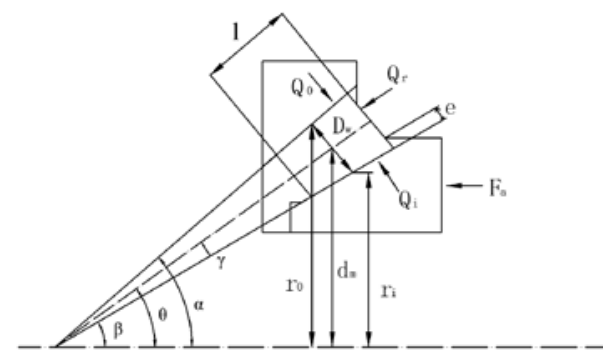

FIGURE II. GEOMETRY OF TAPERED ROLLER BEARING 


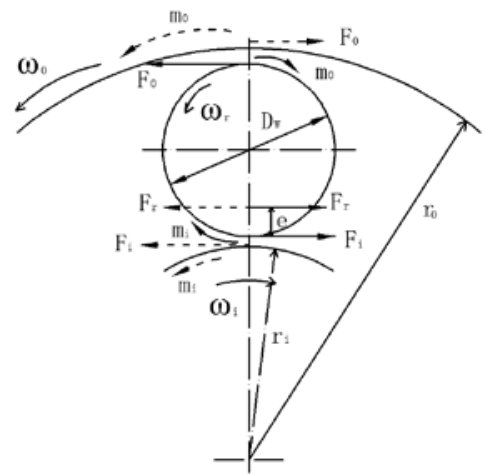

FIGURE III. FORCES AND MOMENTS OF SINGLE ROLLER

Where $Q_{o}, Q_{i}$ and $Q_{r}$ are load that act on the rollers from the outer raceways, inner raceway and rib respectively; $F_{o}, F_{i}$ and $F_{r}$ are frictional forces of outer ring, inner ring and ribroller end contact, and $F_{r}=\mu_{r} Q_{r} ; \mu_{r}$ is the coefficient of friction at rib-roller end contact; $m_{i}$ and $m_{o}$ are viscous rolling resistance of roller-inner raceway contact and roller-outer raceway. Because the force and torque in a single roller are balanced, The equation can be obtained from Figure. 2 and Figure.3 available:

$$
\begin{gathered}
F_{o}=F_{r}+F_{i} \\
m_{o}+m_{i}=F_{i} D_{w}+F_{r}\left(D_{w}+\frac{l}{2} \sin \gamma-e\right)
\end{gathered}
$$

At the same time, the equation for calculating the friction torque generated by a single roller can be expressed in the lower form by Figure.2 and Figure.3:

$$
M^{\prime}=r_{o} F_{o}-m_{o}
$$

The equation (4) is to analyze the equation obtained by taking the inner ring of the bearing and the roller as a whole. $M$ is expressed from equations(2) (4)as follows:

$$
M^{\prime}=\frac{\left(r_{o}-D_{w}\right) m_{o}+r_{o} m_{i}}{D_{w}}-\frac{r_{o}\left(\frac{l}{2} \sin \gamma-e\right)}{D_{w}} F_{r}
$$

Due to the balance of force in a single roller, we can get the following equation [3]:

$$
\begin{aligned}
Q_{o} & =\frac{F_{a}}{Z \sin \alpha} \\
Q_{i} & =\frac{\sin \alpha \sin \theta+\cos \alpha \cos \theta}{\sin \theta \sin \beta+\cos \beta \cos \theta} Q_{o} \\
Q_{r} & =\frac{\sin \alpha \cos \beta-\cos \alpha \sin \beta}{\sin \theta \sin \beta+\cos \beta \cos \theta} Q_{o}
\end{aligned}
$$

Where $F_{a}$ is axial load; $\mathrm{z}$ is the number of rollers. The equation (6) can be further simplified according to trigonometric function transformation as follows:

$$
\begin{aligned}
& Q_{o}=\frac{F_{a}}{z \sin \alpha} \\
& Q_{i}=Q_{o}=\frac{F_{a}}{z \sin \alpha} \\
& Q_{r}=\frac{\sin 2 \gamma}{\cos \gamma} Q_{o}=\frac{2 \sin \gamma \cos \gamma}{z \sin \alpha \cos \gamma} F_{a}=\frac{2 \sin \gamma}{z \sin \alpha} F_{a}
\end{aligned}
$$

The friction torque generated by a single roller, $M^{\prime}$ is expressed from equations(5)、(7)as follows:

$$
M^{\prime}=\frac{\left(r_{o}-D_{w}\right) m_{o}+r_{o} m_{i}}{D_{w}}+\frac{2 \mu_{r} r_{o}\left(e-\frac{l}{2} \sin \gamma\right) \sin \gamma}{z D_{w} \sin \alpha} F_{a}
$$

According to the equation (8), in order to obtain the equation of the moment of friction with the preload of the bearing as the variable. It is necessary to calculate the viscous rolling resistance $m_{i}$ and $m_{o}$.

\section{Calculation Equation of Viscous Rolling Resistance Based on EHL Analysis}

Viscous rolling resistance is the frictional moment caused by the eccentricity of pressure distribution obtained from EHL contacts. The principle can be expressed in Figure.4 [4].

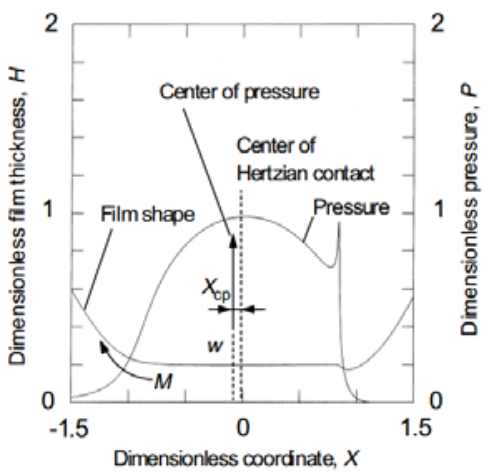

FIGURE IV. VISCOUS ROLLING RESISTANCE M AND THE CENTER OF PRESSURE XCP FOR EHL LINE CONTACT

It can be seen from Figure.4 that due to the uneven distribution of pressure under the EHL effect, the theoretical calculation of viscous rolling resistance becomes very difficult and complex. Therefore, scholars have chosen to obtain the simplified equation of viscous rolling resistance or the whole friction torque by experiments [4-7].

Based on the EHL theory, Goksem-Hargreaves [8] had proposed a dimensionless and dimensional viscous rolling resistance equation as follows:

$$
M=c_{1} \cdot U^{c_{2}} \cdot G^{c_{3}} \cdot W^{c_{4}}
$$




$$
m=\frac{8.636}{\alpha}(G U)^{0.658} W^{0.0126} R^{2} l_{e}
$$

Where $c_{1} \sim C_{4}$ are related constants; $U$ is dimensionless speed parameter, $U=u \eta_{0} / E^{\prime} R ; G$ is dimensionless materials parameter, $G=\alpha E^{\prime} ; W$ is dimensionless load parameter, $W=w / E^{\prime} R ; u$ is mean surface velocity, $\mathrm{m} / \mathrm{s} ; \eta_{0}$ is absolute viscosity at atmospheric pressure, $\mathrm{Pa} \cdot \mathrm{s} ; \mathrm{E}^{\prime}$ is equivalent Young's modulus, $P a$; $R$ is equivalent radius, $m$; $\alpha$ is Pressureviscosity coefficient, $P a^{-1} . l_{e}$ is effective roller resistance, $m$. Aihara and Zhou-Hoeprich [5,6] deduced the corresponding experimental equation based on the theoretical equation of Goksem-Hargreaves. But no matter the theoretical equation deduced by Goksem-Hargreaves or the experimental equation deduced by Aihara, Zhou-Hoeprich and Dwight C. Witte, the equation were obtained under limited conditions. These equations are derived in the case of full flooded. So the equation do not have good versatility.

Based on these problems, H. Matsuyama and S. Kamamoto [4] have put forward an experimental equation which can be widely used. They firstly used the EHL theory to make the viscous rolling resistance dimensionless:

$$
M=\frac{m}{b E^{\prime} l R}
$$

After that, based on the equation (9), H. Matsuyama and S. Kamamoto considered the lubricant starved condition. Besides, they ensured the experimental conditions to satisfy the operating conditions of the automobile drive system. According to the experimental results, the numerical expression form of $c_{1} \sim C_{4}$ are presented by numerical analysis:

$$
\begin{aligned}
& C_{1}=8.89 \\
& C_{2}=-1.1 \exp \left[-4.5\left(\log \left|X_{L 1}\right|\right)^{0.51}\right]+0.75 \\
& C_{3}=-1.0 \exp \left[-5.3\left(\log \left|X_{L 1}\right|\right)^{0.84}\right]-0.04 \\
& C_{4}=1.6 \exp \left[-2.5\left(\log \left|X_{L 1}\right|\right)^{0.72}\right]-0.42
\end{aligned}
$$

Where $X_{\mathrm{L} 1}$ is dimensionless $X$ coordinate of inlet meniscus, $X_{\mathrm{L} 1}=x_{\mathrm{L} 1} / b ; b$ is half width of Hertzian contact, $b=R \sqrt{ }(8 \mathrm{~W} / \pi)$. Full flooded conditions are set at $\left|X_{\mathrm{L} 1}\right|=1000$ by $\mathrm{H}$. Matsuyama, and for staved conditions the meniscus distance, $\left|X_{\mathrm{L} 1}\right|$,is varied from 1000 to 1.05 with irregular intervals. In summary, according to the actual lubrication conditions(the value of $\left.\left|X_{\mathrm{L} 1}\right|\right)$, the viscous rolling resistance of tapered roller bearings can be calculated as follows:

$$
m=14.2 E^{\prime} l R^{2} U^{c_{2}} G^{c_{3}} W^{c_{4}+0.5}
$$

The viscous rolling resistance $m$ under full flooded conditions $\left(\left|X_{\mathrm{L} 1}\right|=1000\right)$ is given by the following equation:

$$
m=14.2 E^{\prime} l R^{2} U^{0.75} G^{-0.04} W^{0.08}
$$

\section{Mechanical Analysis of Main Reducer}

The preload of bearings of driving bevel gear in main reducer is loaded by the tightening of the lock nut. An axial force $F$ is generated by tightening the lock nut, the axial force $F$ is acted on the inner ring of the bearing I through the flange. Three balanced forces are produced as follows:

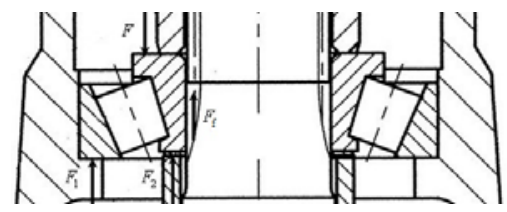

FIGURE V. THE MECHANICAL MODEL OF BEARING I

The relationship among them can be seen as follows:

$$
F=F_{1}+F_{2}+F_{f}
$$

Similarly, for bearing II also has the following relationship:

$$
F^{\prime}=F_{3}+F_{2}+F_{f}^{\prime}
$$

Where $F_{1}$ and $F_{3}$ are forces that act on the bearing block of main reducer from outer ring; $F_{2}$ is the force that act on the supporting sleeve and gasket from inner ring; $F_{f}$ and $F_{f}{ }^{\prime}$ are frictional forces that act on the driving bevel gear from inner ring. $F_{1}$ and $F_{3}$ are the real bearing preload of bearing $I$ and bearing II respectively. Furthermore, because the driving bevel gear in this case is conducted by four forces: lock nut produced equivalent force, $F$; the frictional force that acts on the driving bevel gear from the bearing I and bearing II, $F_{f}$ and $F_{f}$;'the force that acts on the driving bevel gear from the gasket of bearing II .The relationship among them is as follows:

$$
F-F_{f}+F_{f}^{\prime}-F^{\prime}=0
$$

The relation between $F_{1}$ and $F_{3}$ can be obtained from equations (15) (17):

$$
F_{1}=F_{3}
$$

Through the above analysis, it is known that the preload of the two bearings in the main reducer is equal. The equation of the relation between the no-load torque of the main reducer and the preload of the bearing I (or II) is expressed from equations (1), (8), (18) as follows:

$$
\begin{aligned}
& T=z_{1}\left[\left(K_{1}-1\right) m_{o 1}+K_{1} m_{i 1}\right]+z_{2}\left[\left(K_{2}-1\right) m_{o 2}+K_{2} m_{i 2}\right] \\
& +\left(H_{1}+H_{2}\right) F_{a 1}
\end{aligned}
$$

Where $z_{1}$ and $z_{2}$ are roller numbers of bearing $I$ and bearingII respectively; $m_{01}$ and $m_{02}$ are viscous rolling resistances of outer raceway of bearings I and bearings II respectively; $m_{\mathrm{i} 1}$ and $m_{\mathrm{i} 2}$ are viscous rolling resistances of inner raceway of bearings I and bearings II respectively. They can be calculated by the equation (13). $K$ and $H$ are two bearing 
constants sets in this paper. The equation are expressed as follows:

$$
\begin{aligned}
& K=r_{o} / D_{w} \\
& H=\frac{2 \mu_{r} r_{o}\left(e-\frac{l \sin \gamma}{2}\right) \sin \gamma}{D_{w} \sin \alpha}
\end{aligned}
$$

\section{NUMERICAL CALCULATION}

The calculation of viscous rolling resistance requires for the viscosity of lubricant and the pressure-viscosity coefficient of lubricant at working temperature. The parameters of the main reducer lubricant are shown in the following table.

TABLE I. PERFORMANCE PARAMETERS OF VEHICLE GEAR OIL GL-5 75W90

\begin{tabular}{|c|c|}
\hline Kinetic viscosity $\left(\mathbf{m m}^{2} / \mathbf{s}\right)$ & \\
\hline $100^{\circ} \mathrm{C}$ & 14.15 \\
\hline $98.9^{\circ} \mathrm{C}$ & 14.48 \\
\hline $37.8^{\circ} \mathrm{C}$ & 83.93 \\
\hline $30^{\circ} \mathrm{C}$ & 115.83 \\
\hline Viscosity index & 192 \\
\hline
\end{tabular}

When the no-load torque is measured, the working condition of the lubricant is $30^{\circ} \mathrm{C}$ at atmospheric pressure. At this temperature, the kinematic viscosity of the lubricant is $115.83 \mathrm{~mm}^{2} / \mathrm{s}$, and the density is about $0.8801 \mathrm{~g} / \mathrm{cm}^{3}$. So the dynamic viscosity at this temperature is [9]:

$$
\eta_{30^{\circ} \mathrm{C}}=v_{30^{\circ} \mathrm{C}} \cdot \rho_{30^{\circ} \mathrm{C}}=0.1019 \mathrm{pa} \cdot \mathrm{s}
$$

The pressure-viscosity coefficient of lubricant can be calculated by the experimental equation proposed by B.Y.C.So and E.E.Klaus. [10]:

$$
\begin{aligned}
& \alpha=1.216+4.143\left(\log v_{o}\right)^{3.0627}+2.848 \times 10^{-4} C_{o}^{5.1903}\left(\log v_{o}\right)^{1.5976} \\
& -3.999\left(\log v_{o}\right)^{3.0975} \rho^{0.1162}
\end{aligned}
$$

Where $\alpha$ is pressure-viscosity coefficient, $\mathrm{KPa}^{-1} \times 10^{-5} ; \mathrm{w}$ is kinematic viscosity for testing temperature at atmospheric pressure, $\mathrm{mm}^{2} / \mathrm{s} ; C_{o}$ is viscosity-temperature property based on atmospheric kinematic viscosity at $37.8^{\circ} \mathrm{C}\left(100^{\circ} \mathrm{F}\right)$ and $98.9^{\circ} \mathrm{C}\left(210^{\circ} \mathrm{F}\right) ; \rho$ is atmospheric density in $\mathrm{g} / \mathrm{cm}^{3}$ at temperature of interest. The equation proposed by B.Y.C. So and E.E.Klaus predicts the pressure-viscosity coefficient of lubricant at the temperature range from 0 to $135^{\circ} \mathrm{C}$ within 15 percent of the measured values.

The viscosity-temperature parameter $C_{o}$ is a constant to describe the viscosity temperature characteristics of lubricant. It is a parameter in the "Walther equation". Amongst the few rectifying charts available the standardized ASTM kinematic viscosity-temperature chart has certainly achieved the most wide-spread usage. It is based on the MacCoull-Walther equation relating kinematic viscosity to absolute temperature $T$ as follows [11-12]:

$$
\log (\log (v+A))=B-C_{o} * \log (T)
$$

Where $A$ and $B$ are two parameters. ASTM makes the following criteria for the value of $A$ in the Walther equation:

TABLE II. CRITERION OF CONSTANT A IN WALTHER EQUATION

\begin{tabular}{|c|c|c|c|c|}
\hline $\boldsymbol{v}(\boldsymbol{c S t})$ & $>1.5$ & $1-1.5$ & $0.7-1$ & $0.4-0.7$ \\
\hline A & 0.6 & 0.65 & 0.7 & 0.75 \\
\hline
\end{tabular}

When combined with TABLE I, TABLE II and equation (21), it can be calculated that $C_{0}=2.742$. Then the pressureviscosity coefficient at $30^{\circ} \mathrm{C}$ is calculated by equation(20): $\alpha=2.357 \times 10^{-8} \mathrm{~Pa}^{-1}$.According to the lubrication of bearings, the geometric parameters of the main reducer bearings, the viscosity of the lubricant, the pressure-viscosity coefficient and the rotational speed of the work are substituted into the equation (19). The simplified equation of the no-load torque and the preload of the bearing of driving bevel gear is obtained as follows:

$$
T=0.1839 F_{a 1}+13.7576
$$

The unit of $T$ has been converted to $\mathrm{N} / \mathrm{mm}$ in the process of calculation.

\section{DynamiC Simulation ANALysis OF MAin REDUCER GEAR TRANSMISSION SYSTEM}

\section{A. Establishment of Virtual Prototype Model}

In this article, the main parts of the virtual prototype model of the main reducer are driving bevel gear, passive bevel gear, differential shell and differential bearing. And the other parts, such as flange assembly, lock nut, main reducer shell, gasket and sleeve.These parts can be set by the relevant constraints and contact force directly instead of its parts function, they will not affect the motion characteristics of the main reducer gear transmission system. So these parts can be ignored. As for the main research object of this paper, two bearings of driving bevel gear, in order to simulate the effect of the preload of two bearings on the vibration characteristics of the main reducer gear transmission system more accurately. In this paper, two dampers are used to substitute bearings in the ADAMS. view.

Firstly, according to the data in TABLE III, define the material attributes of each part in the "Geometry and Material Type” menu.

TABLE III. MATERIAL PARAMETERS OF EACH COMPONENT OF THE MAIN REDUCER

\begin{tabular}{|c|c|c|c|}
\hline & $\begin{array}{c}\text { Driving,passive } \\
\text { bevel gear }\end{array}$ & $\begin{array}{c}\text { Tapered roller } \\
\text { bearing }\end{array}$ & $\begin{array}{c}\text { differential } \\
\text { shell }\end{array}$ \\
\hline Material & $\mathbf{2 0 C r M n T i}$ & GCr15 & QT500-7 \\
\hline $\begin{array}{c}\text { Young's } \\
\text { modulus } \\
\left(\mathbf{N} / \mathbf{m m}^{2}\right)\end{array}$ & $2.07 \times 10^{5}$ & $2.08 \times 10^{5}$ & $1.66 \times 10^{5}$ \\
\hline $\begin{array}{c}\text { Density } \\
\left(\mathbf{K g} \mathbf{m m}^{3}\right)\end{array}$ & $7.8 \times 10^{-6}$ & $7.8 \times 10^{-6}$ & $9.83 \times 10^{-6}$ \\
\hline Poisson ratio & 0.25 & 0.3 & 0.26 \\
\hline
\end{tabular}

In contact force, the "Impact" mode is chosen to define the parameters required to set the contact force in ADAMS. The stiffness coefficient of the differential and the bearing are calculated according to the following equation [13]: 


$$
K=\frac{4}{3} R^{\frac{1}{2}} E^{*}
$$

Because of the relative extrusion and displacement in the meshing process between the driving bevel gear and the passive bevel gear. The average meshing stiffness of hypoid gears can be calculated as follows [14]:

$$
k_{m}=\left(0.75 \varepsilon_{\alpha}+0.25\right) k_{t h}^{\prime} K_{M} K_{R} K_{B} \cos \beta
$$

Other contact force parameters can be found in reference [13]. The constraints are set according to the actual operating conditions of the main reducer gear transmission system. In this article, the torque transferred from the rear axle to the passive bevel gear is about $500 \mathrm{~N} \cdot \mathrm{m}$, and the torque can be replaced by a one-way torque in ADAMS. Continuously, two dampers are applied at the center of bearing I and bearing II to simulate the radial and axial stiffness of the bearings. Finally, utilize a one-way moment simulate the friction torque of bearings. The virtual prototype model after setup can be seen as follows:

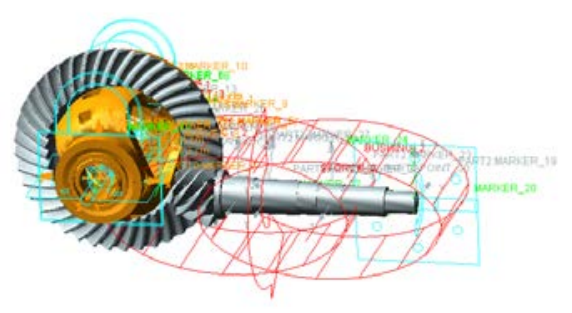

\section{FIGURE VI. VIRTUAL PROTOTYPE MODEL OF THE MAIN REDUCER GEAR TRANSMISSION SYSTEM}

\section{B. The Specific Setting of the Damper and the Resistance Moment Value}

The damper is actually a six component spring structure in ADAMS.view. The damper can set three translation stiffness, three translation damping, three torsional stiffness and three torsional damping between two components. As the preload of bearing mainly affects bearing support stiffness and axial stiffness, therefore, only three translation stiffness functions with preload as design variables need to be set up in this paper.

The relation between the preload and the stiffness of the bearing can be obtained [15]:

$$
\begin{aligned}
& K_{a}=14505 Z^{\frac{9}{10}} l_{e}^{\frac{8}{10}} \sin ^{\frac{19}{10}} \alpha F_{a}^{\frac{1}{10}} \\
& K_{r}=14505 Z^{\frac{9}{10}} l_{e}^{\frac{8}{10}} \sin ^{\frac{9}{10}} \alpha \cos \alpha F_{a}^{\frac{1}{10}}
\end{aligned}
$$

Where $\mathrm{z}$ is the number of rollers; $l_{e}$ is effective roller length, $\mathrm{mm} ; \alpha$ is outer raceway half angle, rad. The no-load torque is divided into seven values. According to equation (22), the preload of the bearing corresponding to the no-load torque can be calculated. The results are as follows:
TABLE IV. SEVEN SETS OF NO - LOAD TORQUE CORRESPONDING TO THE BEARING PRELOAD

\begin{tabular}{|c|c|c|c|c|c|c|c|}
\hline $\begin{array}{c}\boldsymbol{T}(\mathbf{N} \cdot \boldsymbol{m} \\
\boldsymbol{m})\end{array}$ & 600 & 650 & 700 & 750 & 800 & 850 & 900 \\
\hline $\boldsymbol{F a _ { \mathbf { 1 } } ( \boldsymbol { N } )}$ & 3188 & 3460 & 3732 & 4004 & 4275 & 4547 & 4819 \\
\hline
\end{tabular}

The preload of bearing I is set as design variable DV_1, and take the values in TABLE IV. Continuously, set the

\begin{tabular}{|c|c|c|}
\hline Number & Function meaning & Function expression \\
\hline 1 & $\begin{array}{l}\text { Axial stiffness of } \\
\text { bearing } I\end{array}$ & $\begin{array}{c}1.5653582 \mathrm{E}+005 * \\
\mathrm{DV} \_1 * * 0.1\end{array}$ \\
\hline 2 & $\begin{array}{c}\text { Support stiffness of } \\
\text { bearing } I\end{array}$ & $\begin{array}{c}4.3007864 \mathrm{E}+005 * \\
\text { DV_1 }{ }^{* *} 0.1\end{array}$ \\
\hline 3 & $\begin{array}{c}\text { Axial stiffness of } \\
\text { bearing II }\end{array}$ & $\begin{array}{c}2.0884753 \mathrm{E}+005 * \\
\text { DV_1 }{ }^{* *} 0.1\end{array}$ \\
\hline 4 & $\begin{array}{c}\text { Support stiffness of } \\
\text { bearing II }\end{array}$ & $\begin{array}{c}5.7380386 \mathrm{E}+005 * \\
\text { DV_1 }{ }^{* *} 0.1\end{array}$ \\
\hline 5 & $\begin{array}{c}\text { Friction torque of two } \\
\text { bearing }\end{array}$ & $0.1839 * D V \_1+13.7576$ \\
\hline
\end{tabular}
following five functions according to the parameters of the bearing and the parameters in TABLE IV:

TABLE V. FUNCTIONS OF DAMPER AND ONE-WAY TORQUE

The function 5 represents the friction torque of the two bearings.This paper focuses on the influence of preload on the friction torque. Therefore, the change of friction torque caused by the working speed and the thermal effect of the bearing is ignored.

At the same time, the speed of driving bevel gear is set as design variable DV_2. And setting driver start function is "step (time, 0,0,0.2, DV_2)". The range of the daily driving speed of the models studied in this paper is 2000 4500 $\mathrm{r} / \mathrm{min}$. Therefore, in order to simulate operation of the vehicle more idealistically, set six groups of drive speed. They are $800 \mathrm{r} / \mathrm{min}, 1500 \mathrm{r} / \mathrm{min}$, 2000r/min, 3000r/min, 4000r/min and 5000r/min respectively. Finally, use “Design of Experiment” module to simulate.

\section{Analysis of Simulation Result}

In this paper, the angular velocity and acceleration of passive bevel gear and $\mathrm{Y}$ direction meshing force of the hypoid gear are object of study. The vibration of gear transmission system of main reducer is evaluated by RMS values of the three objects. The driving function of this paper is that the speed starts at 0 and reaches the specified speed after $0.2 S$. So we only take the value after $0.2 S$ for statistical analysis. A set of simulation data is taken to show the results of dynamic simulation when DV_1 is 3187.8 and DV_2 is 800 .

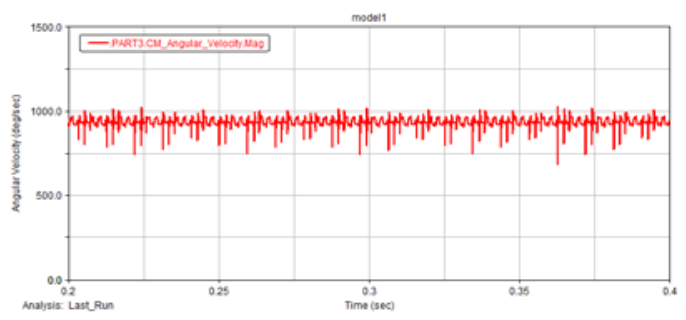

FIGURE VII. THE ANGULAR VELOCITY OF PASSIVE BEVEL GEAR 


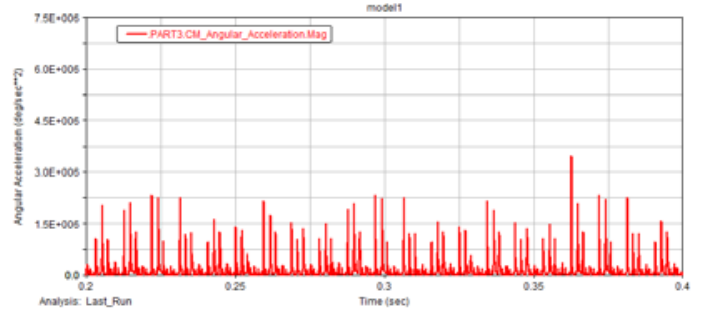

FIGURE VIII. THE ANGULAR ACCELERATION OF PASSIVE BEVEL GEAR

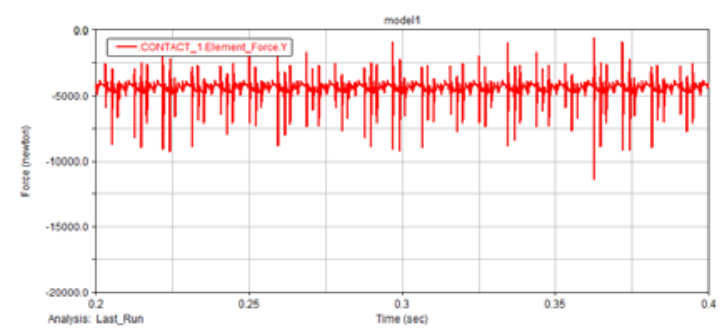

FIGURE IX. THE Y DIRECTION'S MESHING FORCE OF THE HYPOID GEAR

These data of Figure.7 Figure.9 is the first set of data in 42 sets of data. Because of the limited space, these data only shows the first set of simulation results. The Design of Experiment automatically generates 42 sets of data according to the settings of DV_1 and DV_2. After that, the RMS values of the curves are extracted in the post-processing. These data are made into the following chart for more intuitive analysis.

TABLE VI. RMS VALUES OF ANGULAR VELOCITY OF PASSIVE BEVEL GEAR

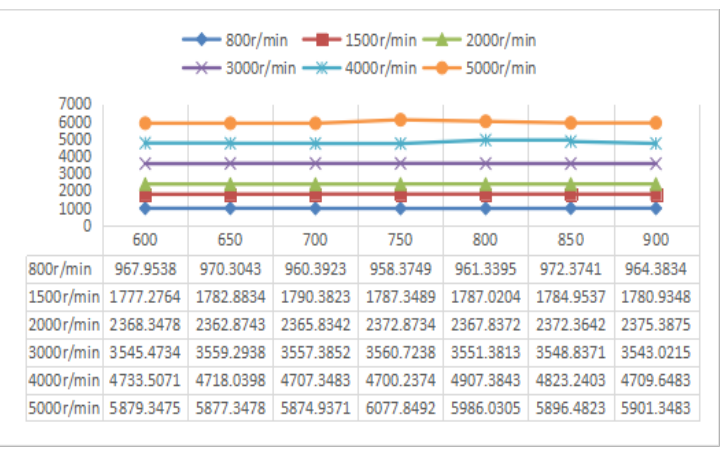

TABLE VII. RMS VALUES OF ANGULAR ACCELERATION OF PASSIVE BEVEL GEAR

\begin{tabular}{|c|c|c|c|c|c|c|c|}
\hline & \multicolumn{7}{|c|}{$\begin{array}{l}\longrightarrow 800 \mathrm{r} / \mathrm{min} \rightarrow-1500 \mathrm{r} / \mathrm{min} \longrightarrow 2000 \mathrm{r} / \mathrm{min} \\
*-3000 \mathrm{r} / \mathrm{min} \rightarrow 4000 \mathrm{r} / \mathrm{min} \rightarrow-5000 \mathrm{r} / \mathrm{min}\end{array}$} \\
\hline \multirow{3}{*}{$\begin{array}{r}2500000 \\
2000000 \\
1500000 \\
1000000 \\
500000 \\
0\end{array}$} & \multirow{2}{*}{\multicolumn{7}{|c|}{ E }} \\
\hline & & & & & & & \\
\hline & 600 & 650 & 700 & 750 & 800 & 850 & 900 \\
\hline $800 \mathrm{r} / \mathrm{min}$ & 424578 & 410737 & 404470 & 401384 & 408753 & 417428 & 428724 \\
\hline $1500 \mathrm{r} / \mathrm{min}$ & 493874 & 483659 & 477760 & 503745 & 523745 & 483476 & 493487 \\
\hline $2000 \mathrm{r} / \mathrm{min}$ & 683478 & 663465 & 660520 & 678764 & 683276 & 678429 & 668003 \\
\hline $3000 \mathrm{r} / \mathrm{min}$ & 693476 & 683247 & 704940 & 723274 & 712764 & 733246 & 726433 \\
\hline $4000 \mathrm{r} / \mathrm{min}$ & 828248 & 823248 & 813170 & 816348 & 903170 & 883247 & 820347 \\
\hline $5000 \mathrm{r} / \mathrm{min}$ & 952487 & 934875 & 926230 & 1926230 & 1118374 & 983487 & 953874 \\
\hline
\end{tabular}

TABLE VIII. RMS VALUES OF THE Y DIRECTION'S MESHING FORCE OF THE HYPOID GEAR

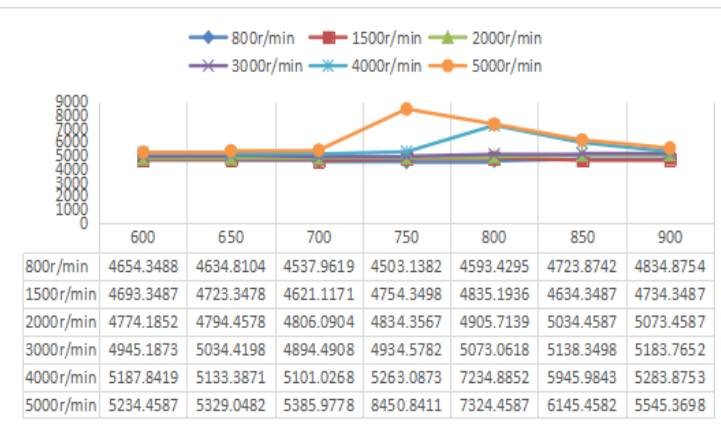

According to TABLE VI, angular velocity is mainly related to the model transmission, and supporting stiffness of the bearing is big enough, so even if the stiffness values change within a certain range, there is little effect on the angular velocity of passive bevel gear. It can be seen from TABLE VII VIII that in the high speed stage, there is a great fluctuation of the angular acceleration of passive bevel gear and the Y direction's meshing force of the hypoid gear at the no-load torque of $750-800 \mathrm{~N} \cdot \mathrm{mm}$. When the no-load torque is between $600-700 \mathrm{~N} \cdot \mathrm{mm}$, the gear transmission is relatively stable. And there is little change in the stiffness of the bearing in this interval, so several values are relatively close. It is difficult to distinguish from the broken line graph. But from the specific numerical comparison, six groups of data show that angular velocity of passive bevel gear, angular acceleration of passive bevel gear and Y direction's meshing force of the hypoid gear of RMS values are smaller when the no-load torque is $700 \mathrm{~N} \cdot \mathrm{mm}$. The results show that the main reducer gear transmission system is more stable when the noload torque is $700 \mathrm{~N} \cdot \mathrm{mm}$.

\section{CONCLUSION}

A number of studies have shown that the stiffness of bearings plays a great role on the vibration of the bearing-rotor system. And the bearing stiffness is determined by the preload of the bearing. In this paper, no-load torque of the main reducer is the basic research object. The mathematical model of bearing preload and no-load torque and bearing stiffness is obtained by theoretical analysis. Then, the no-load torque in the $600-900 \mathrm{~N} \cdot \mathrm{mm}$ interval is discretized into seven values. After that, take the bearing preload as design variable in ADAMS, the simulation results show that the gear transmission system of main reducer has better transmission performance while no-load torque is $700 \mathrm{~N} \cdot \mathrm{mm}$.

\section{REFERENCES}

[1] J. Xu, J. J. Zhang, Z. Q. Huang and L. P. Wang, "Calculation and finite element analysis of the temperature field for high-speed rail bearing based on vibrational characteristics," Journal of Vibroengineering, vol. 17, Issue 2, pp. 720-732, 2015.

[2] K. Yan, N. Wang, Q. Zhai, Y. S. Zhu, J. H. Zhang, and Q. B Niu, "Theoretical and experimental investigation on the thermal characteristics of double-row tapered roller bearings of high speed locomotive," International Journal of Heat and Mass Transfer, vol. 84, pp. 1119-1130, 2015.

[3] Z. J. Liu, Rolling Bearings Application Manual, 3rd ed., Beijing: China Machine Press, 2014, pp. 212-213. 
[4] H. Matsuyama, S. Kamamoto and K. Asano, "The analysis of frictional torque for tapered roller bearings using EHD theory," SAE Technical Paper, 1998.

[5] S. Aihara, "A new running torque equation for tapered roller bearings under axial load," Journal of Tribology, vol. 109, Issue 3, pp. 471-478, 1987.

[6] R. S. Zhou and M. R. Hoeprich, "Torque of tapered roller bearings," Journal of Tribology,vol. 113, Issue 3, pp. 590-597, 1991.

[7] D. C. Witte, "Operating torque of tapered roller bearings," ASLE Trans, vol. 16, Issue 1, pp. 61-67, 1973.

[8] P. G. Goksem and R. A. Hargreaves, "The effect of viscous shear heating on both film thickness and rolling traction in an EHL line Contact-Part I: Fully flooded conditions," Journal of Lubrication Technology, vol. 100, Issue 3, pp. 346, 1978.

[9] F. Z. Zheng and F. Xie, Properties and Applications of Lubricants, Beijing: China Petrochemical Press, 2006, pp. 12-13.

[10] B. Y. C. So and E. E. Klaus, "Viscosity-pressure correlation of liquids," ASLE Trans, vol. 23, Issue 4, pp. 409-421, 1979.

[11] C. J. Seeton, "Viscosity-temperature correlation for liquids," Tribology Letters, vol. 22, Issue 1, pp. 67-78, 2006.

[12] C. J. A. Roelands, W. O. Winer and W. A. Wright, "Correlational aspects of the viscosity-temperature-pressure relationship of lubricating oils (Dr. in dissertation at Delft University of Technology, 1966)," Journal of Lubrication Technology, vol. 93, Issue 1, pp. 209, 1971.

[13] X. F. Lv, Y. Shan and M. Wang,"Tapered roller bearing simulation analysis based on ADAMS," Journal of Harbin Bearing, vol. 35, Issue 2, pp. 5-7, 2014.

[14] W. X. Luo, "Key technology of shaft and rear axle vibration," Master in dissertation at Wuhan University of Technology, 2014.

[15] J. T. Liu, "The research of pre-load for main reducer of automobile's driving axle and the system development," Master in dissertation at Zhejiang University, 2009. 